\title{
A Hot Body in a Cold Room Hyperthermia Secondary to Rapid Diuresis in Cardiac Failure; the Perils of Rapid Fluid Shifts
}

\author{
Boby Varkey Maramattom, Surya Joseph, Siddharth Bhattacharjee, Anil Kumar' ${ }^{1}$, Praveen Sreekumar ${ }^{1}$ \\ Departments of Neurology and ${ }^{1}$ Cardiology, Aster Medcity, Kochi, Kerala, India
}

\section{Abstract}

A 66-year-old man was admitted with anasarca and congestive cardiac failure. He was started on intravenous diuretics and fluid restriction and lost nearly $35 \mathrm{~kg}$ of fluids in 13 days. He then developed hyperthermia and delirium. An extensive workup was inconclusive. Analysis of his inpatient fluid balance chart revealed the chance association of massive fluid loss and hyperthermia. Rapid diuresis-induced hyperthermia and volume contraction were considered, and his fluid balance was adjusted. Within 2 days, his temperature normalized and he regained consciousness. Hyperthermia and its causative mechanism are discussed in this article.

Keywords: Cardiac failure, causes, diuresis, fever, hyperthermia, pump failure, rapid diuresis

\section{INTRODUCTION}

Intensive Care Unit (ICU) patients develop fever due to a variety of causes. Hyperthermia is a condition of impaired thermoregulation and is caused only by a few disorders. We present the case of a 66-year-old man with congestive cardiac failure (CCF) who developed hyperthermia with forced diuresis. Recognition of this association and subsequent fluid management led to a rapid resolution.

\section{Case Report}

A 66-year-old man presented with CCF. He had undergone dual-valve surgery; mitral valve replacement (metallic prosthesis) and aortic valve repair 24 years earlier and was on oral anticoagulation. He had developed massive pedal and scrotal edema and was bedbound for the last 2 weeks. On examination, he was oriented, afebrile, and had massive scrotal edema and anasarca with edema blisters over the legs. He weighed $122 \mathrm{~kg}$. Echocardiography showed paradoxical septal wall motion with a prosthetic mitral valve, left ventricular ejection fraction $35 \%$, dilated right ventricular annulus, moderate left ventricular dysfunction, and severe tricuspid regurgitation. Venous Doppler of the legs was normal. He was started on digoxin and intravenous (IV) furosemide along with fluid restriction. In 13 days, he lost a cumulative fluid of $\sim 35 \mathrm{~L}$ and his body weight was $88 \mathrm{~kg}$. His creatinine rose to

\begin{tabular}{|l|l|}
\hline \multicolumn{2}{|c|}{ Access this article online } \\
\hline Quick Response Code: & Website: \\
\hline & www.ijccm.org \\
\hline & \\
\hline
\end{tabular}

$3.2 \mathrm{mg}$ and bilirubin to $2.7 \mathrm{mg}$; however, an ultrasonography abdomen was normal. Ammonia (195 mg) was elevated, with normal liver enzymes and serum electrolytes. By day 13 , his temperature crept up to $41^{\circ} \mathrm{C}\left(106^{\circ} \mathrm{F}\right)$ and he became delirious. His creatine phosphokinase was $6500 \mathrm{U} / \mathrm{L}$ and lactic dehydrogenase was 720 U/L. Sepsis was considered and empirical antibiotics were administered. Computed tomography brain and pan cultures were normal. He was initiated on hemodialysis and hepatic encephalopathy regimen. Muscle tone was normal, and he was warm and "dry." He was intubated and ventilated. He had not been administered any neuroleptics, serotonergic agents, or anesthetic agents. Analysis of his intake-output chart led us to consider forced diuresis-induced hyperthermia at this point [Figure 1]. The ICU Wet Bulb Globe Temperature (WBGT) was approximately $78^{\circ} \mathrm{F}\left(25.5^{\circ} \mathrm{C}\right)$. His fluid balance was controlled, and cooling blankets and cold IV fluids were instituted. Pan cultures were negative. His temperature came down to $37^{\circ} \mathrm{C}$ over 3 days; he regained consciousness and hemodialysis was stopped after 5 days. His weight stabilized at $95 \mathrm{~kg}$. He was discharged without further incident.

Address for correspondence: Dr. Boby Varkey Maramattom, Department of Neurology, Aster Medcity, Kochi - 682 023, Kerala, India. E-mail: bobvarkey@gmail.com

This is an open access journal, and articles are distributed under the terms of the Creative Commons Attribution-NonCommercial-ShareAlike 4.0 License, which allows others to remix, tweak, and build upon the work non-commercially, as long as appropriate credit is given and the new creations are licensed under the identical terms.

For reprints contact: reprints@medknow.com

How to cite this article: Maramattom BV, Joseph S, Bhattacharjee S, Kumar A, Sreekumar P. A hot body in a cold room hyperthermia secondary to rapid diuresis in cardiac failure; the perils of rapid fluid shifts. Indian J Crit Care Med 2018;22:608-10. 


\section{Discussion}

Temperature regulation is an intricate process masterminded by the hypothalamus [Figure 2].

Internal heat is generated via metabolism and muscle contraction. The excess "waste" heat is lost to the environment through radiation $\left(\mathrm{H}_{\mathrm{rad}}\right)$, convection $\left(\mathrm{H}_{\text {conv }}\right)$, conduction $\left(\mathrm{H}_{\mathrm{k}}\right)$ (sensible heat) (dry heat loss [DHL]), and evaporation $\left(\mathrm{H}_{\text {evap }}\right)$ (latent heat). With exercise, increasing metabolism, or increasing environmental temperatures, the first three methods (DHL) are limited and primary heat loss is through evaporation. The environmental WBGT (an index of heat stress) also influences the rate of $\mathrm{H}_{\text {evap }}{ }^{[1]}$ The WBGT (a combination of air temperature, mean radiant temperature, absolute humidity, and air movement) is a widely used index of heat stress. As the WBGT increases, the heat stress increases.

Thus, a thermo-neutral heat balance equation is one where heat production equals heat loss and is represented by the following equation: ${ }^{[2]}$

$\mathrm{S}=\left(\mathrm{H}_{\mathrm{m}}-\mathrm{W}_{\mathrm{e}}\right) \pm \mathrm{H}_{\text {evap }} \pm \mathrm{H}_{\text {Conv }} \pm \mathrm{H}_{\mathrm{rad}} \pm \mathrm{H}_{\mathrm{k}} \pm \mathrm{H}_{\mathrm{r}}$

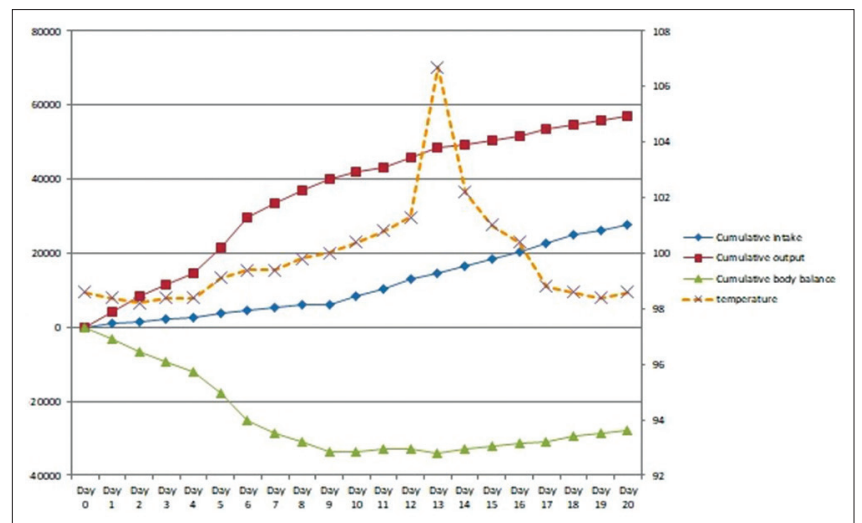

Figure 1: Graph showing the relationship between intake, output, and cumulative body water loss with body temperature
Where $\mathrm{S}=$ Change in body heat content

$\mathrm{H}_{\mathrm{m}}=$ Internal metabolic heat

$\mathrm{W}_{\mathrm{e}}=$ External work performed

$\left(\mathrm{H}_{\mathrm{m}}-\mathrm{We}\right)=$ Heat to be dissipated to the surrounding ("Waste heat")

$\mathrm{H}_{\text {evap }}=$ Evaporative heat loss from the body

$\mathrm{H}_{\text {Conv }}=$ Convective heat loss

$\mathrm{H}_{\mathrm{rad}}=$ Radiated heat loss

$\mathrm{H}_{\mathrm{k}}=$ Conductive heat loss

$\mathrm{H}_{\mathrm{r}}=$ Heat loss through respiration.

For normal heat balance, $\mathrm{H}_{\mathrm{m}}-\mathrm{W}_{\mathrm{e}}$ ("Waste heat") = $\mathrm{H}_{\text {evap }} \pm \mathrm{H}_{\text {Conv }} \pm \mathrm{H}_{\text {rad }} \pm \mathrm{H}_{\mathrm{k}} \pm \mathrm{H}_{\mathrm{r}}$. When there is an imbalance either by increase in $\mathrm{H}_{\mathrm{m}}$ or a decrease in $\mathrm{H}_{\text {evap }} \pm \mathrm{H}_{\text {Conv }} \pm \mathrm{H}_{\text {rad }} \pm \mathrm{H}_{\mathrm{k}} \pm \mathrm{H}_{\mathrm{r}}$, then the body accumulates heat.

In cool environments, our excess heat load is dissipated to the environment by radiation and convection from our skin. With increasing workloads or higher environmental temperatures, evaporative cooling is the primary heat loss mechanism. Hence, when evaporative cooling is hindered by dehydration, clothing, increasing humidity, or poor air movement, human beings become vulnerable in high temperatures.

Hyperthermias are disorders of increased body temperature. These can be broadly classified as fever or hyperthermic states. Whereas fever is induced by an elevation of the hypothalamic set point and is aspirin responsive; in the other hyperthermic states, the hypothalamus and the temperature regulatory circuitry are overwhelmed. Hyperthermia classically is defined as a core body temperature $>40^{\circ} \mathrm{C}-40.5^{\circ} \mathrm{C}$ along with central nervous system dysfunction. ${ }^{[3-5]}$

True hyperthermia is due to (1) excessive heat production as in exercise hyperthermia; (2) impaired heat dissipation as in



Figure 2: Hypothalamic thermoregulation 
dehydration, environmental heat exposure, skin diseases, or anhidrosis; or (3) pathological or pharmacological factors that impair thermoregulatory mechanisms [Figure 3].

Surprisingly, CCF is associated with an increased basal metabolic rate (BMR) of approximately $18 \%$ more than normal, which contributes to cardiac cachexia. ${ }^{[6]}$ Furthermore, the BMR increases in direct proportion to the severity of the heart failure. ${ }^{[7]}$

Furosemide has been implicated in hyperthermia in rare cases, due to either drug fever or dehydration in a neonate and as an idiosyncratic reaction in an adult. ${ }^{[8,9]}$ However, this magnitude of dehydration and the correlation with rising temperature have not yet been documented.

The rate of heat loss at rest in an air-conditioned room is approximately $370 \mathrm{~kJ} / \mathrm{h}$ (sensible heat $210 \mathrm{~kJ} / \mathrm{h}$ and latent heat $160 \mathrm{~kJ} / \mathrm{h}$ ). ${ }^{[10]}$ Usually, heat-related illness is uncommon with a WBGT $<82^{\circ} \mathrm{F}\left(28^{\circ} \mathrm{C}\right)$. Although our ICU was relatively "cold" with a WBGT of approximately $78^{\circ} \mathrm{F}\left(25.5^{\circ} \mathrm{C}\right)$, we presume that our patient developed hyperthermia by the following mechanisms:

1. Increased heat production $\left(\mathrm{H}_{\mathrm{m}}\right)$ as $\mathrm{CCF}$ is associated with a raised $\mathrm{BMR}^{[6]}$

2. Inability to increase heart rate and stroke volume by the failing heart "pump failure," leading to internal heat accumulation

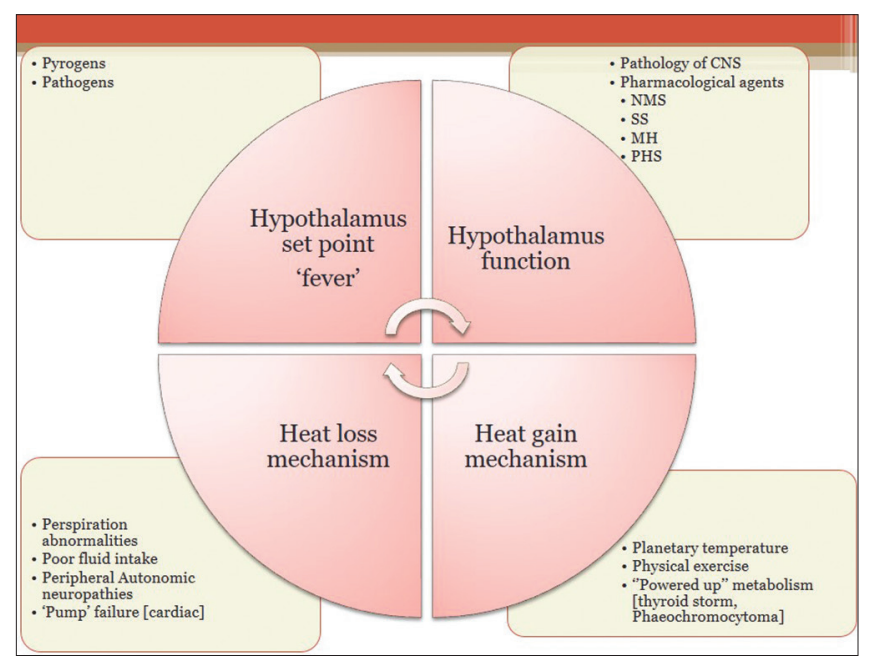

Figure 3: Conditions that cause an elevation of body temperature by interfering with different aspects of temperature control; the 11 Ps
3. Intravascular volume depletion secondary to massive diuresis - reduced heat carried to periphery for dissipation

4. Diuresis-induced peripheral vasoconstriction

5. Immobility and reduced behavioral adaptive responses worsening the spiral of heat accumulation and hyperthermia.

Hence, in our patient, the heat balance equation tilted toward heat retention "by increased $\mathrm{H}_{\mathrm{m}}$ and reduced $\mathrm{H}_{\text {evap }}$, with the other five variables remaining constant. The massive forced diuresis, underlying "pump" failure, and general debility contributed to accumulation of a "heat load" and hyperthermia. Physicians should consider an acutely impaired fluid balance as a possible cause of fever or hyperthermia in the ICU. The traditional "start low, go slow" technique of diuresis and close attention to the fluid balance are preferable even in severe cardiac failure, to avoid such a calamitous complication.

\section{Financial support and sponsorship}

Nil.

\section{Conflicts of interest}

There are no conflicts of interest.

\section{RefEREnCes}

1. Budd GM. Wet-bulb globe temperature (WBGT) - Its history and its limitations. J Sci Med Sport 2008;11:20-32.

2. Budyko MI, Tsytsenko GW. Climatic factors of thermal sensations of the man - Ser Geogr 1960;3:3-11.

3. McGeehin MA, Mirabelli M. The potential impacts of climate variability and change on temperature-related morbidity and mortality in the United States. Environ Health Perspect 2001;109 Suppl 2:185-9.

4. Wexler RK. Evaluation and treatment of heat-related illnesses. Am Fam Physician 2002;65:2307-14.

5. Atha WF. Heat-related illness. Emerg Med Clin North Am 2013;31:1097-108.

6. Poehlman ET, Scheffers J, Gottlieb SS, Fisher ML, Vaitekevicius P. Increased resting metabolic rate in patients with congestive heart failure. Ann Intern Med 1994;121:860-2.

7. Obisesan TO, Toth MJ, Donaldson K, Gottlieb SS, Fisher ML, Vaitekevicius $\mathrm{P}$, et al. Energy expenditure and symptom severity in men with heart failure. Am J Cardiol 1996;77:1250-2.

8. Garty BZ. Furosemide-associated fever: Drug fever or dehydration fever? J Pediatr 1997;130:499-500.

9. Ebdrup L, Pedersen CM, Andersen MH, Storgaard M. Prolonged hyperthermia from furosemide infusion - A case report. Eur J Clin Pharmacol 2010;66:215-6.

10. Wankhade SP, Mujawar RY. Recent trends in modes of heat dissipation from the human body. Recent trends in Mechanical engineering, 2016. Int J Innov Eng Res Technol 2016:2394-3696. 